\title{
Intermittent fasting: five quick questions with fasting expert Brad Pilon
}

$\mathrm{B}$ rad Pilon left a high-paying job in the bodybuilding supplement industry to pursue graduate studies on the metabolic effects of short-term fasting at the University of Guelph in Ontario. One result of that research was his popular book on intermittent fasting, Eat Stop Eat. Below, Pilon explains his ideas on how fasting once or twice a week for up to 24 hours can improve health, and why those ideas tend to be controversial.

CMAJ: In a nutshell, what is your philosophy on fasting?

Pilon: The thesis I want to get across to people is that there are health benefits, including weight loss, to being able to take an occasional break from eating. Rather than just looking at it as fasting, which can have a negative connotation, it's more about breaking the cycle of thinking you can't take the occasional break from eating.

CMAJ: Why not just go on a traditional diet?

Pilon: Dieting is a slow, inevitable march to failure. ... You are constantly getting to eat, so you don't learn to be patient, knowing that a good meal is going to come. And you have to make tonnes and tonnes of food-based decisions. By deciding to diet, you largely increase the amount of your mind space that's preoccupied with food.

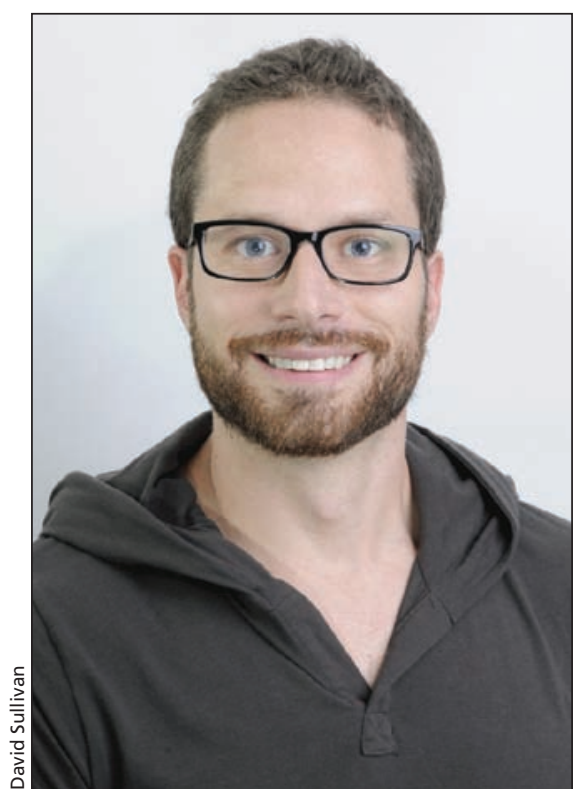

A traditional diet is a "slow, inevitable march to failure," says intermittent fasting advocate Brad Pilon.

CMAJ: Rather than eat less to lose weight, couldn't a person exercise more instead?

Pilon: The average person who is overweight but not actively trying to lose weight often says they just don't have time to exercise. But that has little to do with it. You actively have time to eat less.

CMAJ: Do people sometimes react negatively to the idea of fasting for weight loss?
Pilon: It's the same as talking religion or politics in terms of how angry people can get. When the answer is simple, there is a certain amount of resistance to it. If you tell people the answer is eating less, to them, the obvious thing you are throwing in their face is that you spent a good deal of time eating too much.

$\boldsymbol{C M A J}$ : Has fasting reached the mainstream?

Pilon: It's hitting that point where it's definitely going to be a fad. There's no way around it. The concern is that people who give health advice automatically think anything that's a fad is bad. So we might throw the baby out with the bathwater. If we could look at it as a way to explain to people that they don't necessarily have to eat all the time, and keep some of the benefits of it, then I think there can be some serious benefits to the style that people eat. - Roger Collier, CMAJ

CMAJ 2013. DOI:10.1503/cmaj.109-4438

Editor's note: This is a follow-up to previous news stories at cmaj.ca: "Intermittent fasting: the next big weight loss fad" and "Intermittent fasting: the science of going without." 